\title{
Myofascial Pain, Fibromyalgia or Fibrositis?
}

\author{
J.M.S. Pearce \\ Emeritus Consultant Neurologist, Department of Neurology, Hull Royal Infirmary, Hull, UK
}

\section{Key Words}

Myofascial pain · Fibromyalgia $\cdot$ Fibrositis $\cdot$ Nociceptor . Central pain

\begin{abstract}
The terms myofascial pain, fibromyalgia and fibrositis are critically examined. They constitute diagnostic labels for non-specific musculoskeletal aches and pains. Analysis of the evidence shows that none of these labels is substantiated by hard physical signs or by laboratory evidence of consistent pathological or biochemical abnormality. What is the objective evidence for disorder(s) of muscle, fascia or fibrous tissues, so clearly indicated by these diagnostic names? Alternative terms such as 'regional pain syndrome' or 'chronic pain syndrome' merely redefine the clinical problem without providing a mechanism or basis for diagnosis. Despite different diagnostic criteria, these conditions, along with chronic fatigue syndrome, have many demographic and clinical similarities, most notably tender trigger points. Indeed, the terms are often used interchangeably. There are few differences in the symptoms, physical findings, laboratory tests, functional status, psychosocial features and psychiatric disorders. This paper seeks not to deny the existence of aches and pains, but to critically examine the
\end{abstract}

\section{KARGER}

Fax + 41613061234

E-Mail karger@karger.ch

www.karger.com
(C) 2004 S. Karger AG, Basel

0014-3022/04/0522-0067\$21.00/0

Accessible online at:

www. karger.com/ene utility of these terms. The only claimed physical sign is the presence of tender trigger points over muscles or muscle attachments. Research suggests that tender points are a measure of general distress related to pain complaints but separately associated with fatigue and depression. They are present in some normal subjects and are variable in occurrence in time in the same individual. They reflect no demonstrable pathology. It is therefore argued that none of these commonly used diagnoses represent distinct disease entities. A possible but unproven alternative hypothesis is that such symptoms relate to neural pain with both peripheral and central components, and in some instances psychological or wilful embellishment.

Copyright $@ 2004$ S. Karger AG, Basel

'Belief like any other moving body follows the path of least resistance.'

Samuel Butler (1612-1680)

A wide variety of painful syndromes has for many years been attributed to a disorder of muscles, tendons, ligaments and fascia. Chronic backache, neck ache, temporomandibular joint syndrome and a variety of pelvic, limb and chest wall pains have been explained on this 
basis. Yet such attribution is at best conjectural since there is a striking dearth of physical signs or investigations, which would serve to validate myofascial pain, fibromyalgia (FM) or fibrositis as explanations, or to provide a convincing objective basis for the symptoms.

Painful muscles, tendons and ligaments are common, but usually symptoms are short-lived and pose no lasting medical problems. For over 100 years they were called muscular rheumatism, rheumatic neuralgia (Gowers) or fibrositis to distinguish them from arthritis, a condition with pathology demonstrable within joints [1]. Rheumatism was ascribed to inflammation of fibrous tissues in bursae, tendons, ligaments, fascia, muscles and nerve sheaths [2]. More often rheumatism was used to imply an undefined, but essentially transient benign non-specific inflammation [1].

Ten years ago Henriksson noted: 'The conclusion is that no one single mechanism can explain FMS and is thus in that sense a compromise. FMS [fibromyalgia syndrome] in some patients may start in the muscle, in other patients in the brain. The combination of peripheral and central factors is the key to the pathogenesis of FMS as long as FMS is defined as a pain syndrome' [3]. This paper aims not to deny the existence of aches and pains, but to critically examine (like Henriksson) the utility of the terms myofascial pain, FM and fibrositis.

\section{Fibrositis}

Sir William Gowers in 1904 [4] invented the term:

'I think we need a designation for inflammation of the fibrous tissue which has not such results [sc. the production of induration or suppuration] ... We may conveniently follow the analogy of cellulitis and term it fibrositis.'

Fibrositis could spread to the fascial investments of adjacent tendons, joints and nerve sheaths, thus explaining for example some instances of 'interstitial sciatic neuritis'. A British Medical Association committee in 1933 recognized subgroups of fibrositis [5]: intramuscular and fascial; periarticular; bursal and tenosynovial; subcutaneous (panniculitis), and perineuritic. 'Perineuritis' could cause radiating pain, paraesthesiae, cutaneous hyperaesthesia, tenderness in muscles and joints within the sensory innervation and local nerve tenderness attributed to the involvement of the nervi nervorum.

Slowly the concept of the fibrositic nodule arose, 'an area in the substance of a muscle or its tendinous sheath which gives rise to localized pain or referred pain at a dis- tance when stimulated' [6], but it fell from favour because nobody could show a pathology [7]. Some still speculated without proof on regional pain syndromes caused by a pathology so subtle that it could not be demonstrated; they called this myofascial pain syndrome (MPS).

\section{Fibromyalgia}

FM has more recently been invoked to account for chronic and widespread musculoskeletal pains [8]. According to the diagnostic criteria for FM syndrome published by the 1990 American College of Rheumatology, FM patients must have: (1) widespread pain in all four quadrants of their body for a minimum of 3 months; (2) at least 11 of the 18 specific tender points. Commonly associated symptoms include: fatigue, sleep disorder, temporomandibular joint dysfunction, postexertion malaise and muscle pain, numbness and tingling, skin sensitivities, morning stiffness, irritable bowel, chronic headaches (tension type or migraines), cognitive or memory impairment, menstrual cramping and premenstrual syndrome, dizziness or impaired coordination.

FM shares many similarities with myofascial pain, chronic fatigue syndrome and fibrositis $[9,10]$. The notable authorities, Cohen and Quintner [9], state:

'Its pathophysiology, physical and psychological, is unknown, and the nature of the allegedly mandatory TPs [trigger points] remains obscure. Diagnostic criteria convey no pathophysiological insight and they have been 'validated' via a circular argument in which the evidence on which the construct is based is taken as proof of its veracity. The concept of fibromyalgia syndrome is valid only in the sense that it includes all possibilities. An alternative approach is to consider secondary hyperalgesia.'

\section{Tender Trigger Points}

Trigger points (TPs) are allegedly an important sign of MPS and FM. A classic TP is defined as the presence of discrete focal tenderness located in a palpable taut band of skeletal muscle, which produces both referred regional pain (zone of reference) and a local twitch response. TPs are used to define MPSs. Tender points, by comparison, are associated with 'pain at the site of palpation only, are not associated with referred pain and occur in the insertion zone of muscles, not in taut bands in the muscle belly' [11]. By definition [12], patients with FM have tender 
points, but patients with MPS may also have TPs; these two pain syndromes may therefore overlap and be difficult to differentiate.

The mechanism of myofascial pain with characteristic TPs and taut bands is said to be a spinal reflex disorder caused by a reverberating circuit of sustained neural activity in a specific spinal cord segment. However, this is conjecture unsubstantiated by experimental data. When blinded to the diagnosis, experts in MPS found TPs in only $18 \%$ of subjects with a diagnosis of MPS [13]. In the same study, assessments for taut bands and muscle twitch responses were also found to be 'unreliable'.

How useful are TPs? Unfortunately there is a dearth of large series and no independent hallmark by which the diagnoses can be validated. One study reported [14] 250 subjects selected from participants in a chronic pain survey who had a TP examination. Of these, 100 had chronic widespread pain, 100 regional pain and 50 no chronic pain. On the day of examination, pain in many patients had shifted. For instance $3 / 74$ with stated chronic widespread pain now had no pain, and 7/39 with no chronic pain now had chronic widespread pain. According to their status on the day of examination, the criterion of 11 of 18 painful TPs was found in $40 \%$ of patients with chronic widespread pain, $20 \%$ of those with regional pain and $5 \%$ of those with no pain. Overall 20 of 132 patients without one of the two criteria of FM had at least 11 painful TPs. By contrast, 29\% of patients with chronic widespread pain had only 0-4 painful points. In this study, Croft et al. [14] observed that similar sites are common in asymptomatic individuals:

'The distinctive sign is tenderness to pressure at specific sites over muscles or muscle attachments. Tender points are a measure of general distress. They are related to pain complaints but are separately associated with fatigue and depression ... Fibromyalgia does not seem to be a distinct disease entity.'

The criterion of 11 painful TPs thus appears unreliable: a poor diagnostic test. There is no gold standard against which they can be measured. Experts elicit different numbers in the same patients $[13,14]$.

These findings cast serious doubt on the internal validity of the concept. The TPs vary from person to person and from hour to hour. Proponents consider TPs as latent or dormant if not causing referred pain. Latent TPs are thought to increase with age. Satellite TPs are in muscles within the pain reference zone of another TP. Secondary TPs develop in muscles that are either synergists or antagonists of the muscle primarily affected. Synergists are said to be overloaded when they substitute for the affected muscle, and antagonists are overloaded when they counter its tautness. The chronicity of pain that follows stimulation by palpation or electrical stimulus of a myofascial TP is explained by a feedback cycle maintained by the central nervous system (CNS) receiving impulses arising in the TPs. But since the painful muscles in MPS are electrically silent, the suggestion of myofibrillar or myofascicular contraction is highly improbable [15]. Furthermore, the efferent $\gamma$-motoneuron activity was diminished rather than increased in muscles with carrageenan-induced injury [16]; thus, these authors concluded that these models 'have to be considered as working hypotheses rather than explanations of known mechanisms'. They later showed that at all central nervous levels the connections and processing of nociceptive information from muscle and skin are different. They deduced that a dysfunction of descending pain-modulating pathways could lead to chronic deep pain as in fibromyalgia. This remains hypothetical since the data were partly from anaesthetized rats, and partly from healthy subjects or FM patients [17].

Chronic fatigue syndrome and FM [18] are clinical conditions both characterized by a variety of non-specific symptoms including prominent pain near muscles, fatigue and sleep disturbances. 'Many researchers now believe patients with the chronic fatigue syndrome have many similarities with FM patients [19, 20], and about $75 \%$ of patients meeting the diagnostic criteria of chronic fatigue syndrome also meet the criteria for a diagnosis of FM.

There are no diagnostic investigations or widely accepted pathogenic mechanisms for either illness. Despite different diagnostic criteria, chronic fatigue syndrome, MPS and FM have many demographic and clinical similarities including TPs. The terms are often (mis)used interchangeably. There are few differences in the symptoms, physical findings, laboratory tests, functional status, psychosocial features and psychiatric disorders [21].

Myofascial TPs may be initiated by many diverse precipitants: trauma, muscular strains, chilling of fatigued muscle or nerve root injury [22]. These same factors are also said to be capable of activating latent TPs [23]. These injuries are thought to release neurokinins, histamine, serotonin and prostaglandins, which stimulate nociceptors and cause reflex muscle contraction. But the evidence does not support this concept. Muscle pain and damage following eccentric contractions have been studied [24]. In normal subjects, unless there are muscle tears or deep haematomata, recovery from injury is complete. Electromyography of painful muscles [15] and thermographic 
studies [25] have not shown diagnostic abnormalities in TPs. Muscle biopsies of TPs have shown no consistent muscle inflammation or damage.

\section{Myofascial Pain Syndrome}

The term myofascial pain [26] was introduced in 1952 and developed by Travell and co-workers [22, 27]. It has been defined as a regional pain syndrome with: (1) the TP, a localized area of deep muscle tenderness or hyperirritability, and (2) a predictable, discrete reference zone of deep aching pain, which may be located in the immediate region of or remote from the $\mathrm{TP}$, may be quite extensive and is worsened by palpation of the TP.

TPs have been described in the skin, joint capsules, ligaments and periosteum as well as in muscles and their fasciae. The clinical and epidemiological features overlap impressively with FM, fibrositis and chronic fatigue. On 'snapping', palpation or needling of a myofascial TP, a local twitch response can be elicited. This is accompanied by an irritable electromyographic response. A muscle containing a TP is said to exhibit antalgic inhibition when tested for strength and is intolerant to stretch. Inactivation of the relevant TPs by physical or chemical means is needed to relieve pain. The specific muscle or muscle group that causes the symptoms should be identified. TPs are nonetheless said to be maintained via the CNS, not only by their own activity but also by many processes associated with afferent neural input. Central sensitization is claimed to involve 'wind-up phenomena' due to activation of $\mathrm{N}$-methyl- $D$-aspartate receptors on secondorder neurons in the brainstem. Derangements in descending endogenous pain-modulating systems due to central serotonin deficiency may explain the disordered antinociception. Simons and Travell [23] have somewhat vaguely defined MPS as 'primarily a dysfunction of one or more specific muscles'. Myofascial TPs have no gold standard diagnostic criterion [28].

It is difficult to ignore the fact that the proponents of MPS [22; for extensive literature, see ref. 29] have included their conclusions and beliefs within their defining, diagnostic criteria. Unfortunately this elementary error in logic and reasoning largely invalidates any consideration of other possible explanations of the symptoms as they define them.

The definition of MPS is fallacious since its definition incorporates the very hypothesis it seeks to prove: an example of circular reasoning. The permitted number and nature of predisposing, precipitating and perpetuating factors is vast and includes the full spectrum of supposed aetiologies of MPS and the related 'syndromes' mentioned [10, 16, 23, 24]. This reiterates the circular reasoning. Trying to provide external confirmation of their notion, researchers say that TPs arise from muscle damage, despite electrical silence and the lack of histological or biochemical abnormality. But, there is neither support from an animal experimental model nor from studies of human muscle damage or injury [24]. Spread of pain is attributed to the activation of latent TPs or to the "metastasis' of TPs. This teleological argument is physiologically unsound. Taken together, the evidence on which MPS is founded arises from an illogical definition.

\section{Possible Basis of Soft Tissue Pain}

The pain in question has the features of deep somatic pain. By the 1930s, the experiments of Sir Thomas Lewis [30] and Kellgren [31] convincingly demonstrated distant referral of somatic pain, such as originates in muscles, tendons and bone. Kellgren [31] noted:

'The diffuse pain from a given muscle is always distributed within certain regions, though the distribution within these limits varies from individual to individual, and according to the part of the muscle stimulated' and 'pain from muscle may be confused with pain arising from other deep structures such as joints and testis.'

It is prudent to be cautious in diagnosing the precise origin of such pain. The roles of psychogenic, central and peripheral neural mechanisms may each be relevant. Afferents from sites of referred muscle pain are the same as those that act centrally on the spinal neurons that process 'pain information' from deep structures, thus leading to central summation [32] and probable enhancement. Pallor, cyanosis, hypo-aesthesia and abnormal sweating are commonly seen in the skin overlying a source of deep somatic pain. These phenomena occur commonly and normally in a limb immobilized after fracture, the immobility being an important causal feature (invariably present in reflex sympathetic dystrophy). These signs may be explained as somatic referred pain [33]. Since human peripheral nerves are well innervated by nervi nervorum [34], peripheral neural pain may also be important. Nerve trunk pain may simulate myofascial pain. Such pain has been attributed to increased activity in mechanoceptors and nociceptors, within the neural sheath. Pain with the characteristics of 'nerve trunk pain' is recognized in patients with irritative cervical and lumbar radiculopathy [35] and with peripheral nerve injury [36]. 
Hyperalgesia in muscles that are structurally and electrically normal suggests that the hyperalgesia [37] is referred owing to peripheral antidromic activation or sensitization [38] of nociceptive afferents or results from central sensitization of nociceptive dorsal horn neurons [39]. Radiation of pain and tenderness may depend on altered central processing held responsible for secondary hyperalgesia maintained by nociception arising in peripheral nerves. But these factors still leave us without any good explanation of a mechanism to account for the persistence of aches and pains after a self-limited or unknown primary 'illness or injury'.

\section{Conclusion}

A painful condition of soft tissues is undoubtedly a genuine entity, though as a consequence of sprain or trau$\mathrm{ma}$ it is usually short-lived. Persistent or recurrent soft tissue pain is commonly ascribed to MPS or FM, and criteria have been generally accepted. It is suggested that MPS, fibrositis and FM simply redefine the problem of aetiology and, as the explanation of chronic, deep, aching, poorly localized pain, lack both internal and external validity.

Fallacies in this concept include a logically implausible, circular definition of MPS that incorporates a theory of its cause. TPs, commonly used in diagnosis, are nonspecific and clinically unreliable. Both predisposing and precipitating factors are numerous and occur in many other pain syndromes. Histological, biochemical and electrical evidence of causal pathology is lacking, and experimental human models of muscle injuries yield no consistent pathogenetic findings. A neural basis, involving central pain and/or peripheral hyperalgesia though equally unproven, is a more attractive hypothesis. Psychogenic factors and motives, outside the scope of this study, are important, particularly in persistent pain.

\section{Acknowledgement}

This review was stimulated by the writings of many authors, particularly M.L. Cohen, J.L. Quintner, R.M. Bennett and F. Wolfe.

\section{References}

1 Reynolds MD: The development of the concept of fibrositis. J Hist Med Allied Sci 1983; 38:5-35.

2 Aitken W: The Science and Practice of Medicine. London, Charles Griffen \& Co, 1866, vol 2, 6-37, pp 629-630.

3 Henriksson KG: Chronic muscular pain: Aetiology and pathogenesis. Baillières Clin Rheumatol 1994;8:703-719.

4 Gowers WR: Lumbago: Its lessons and analogues. Br Med J 1904;1:117-121.

5 Bach F: The Rheumatic Diseases: Their Recognition and Treatment. London, Cassell, 1935, pp 4, 6 .

6 Copeman WSC: Aetiology of the fibrositic nodule: A clinical contribution. Br Med J 1943;2: 263-264.

7 Collins DH: Fibrositis and infection. Ann Rheum Dis 1940;2:114-126.

$>8$ Wolfe F, Smythe H, Yunus MB, Bennett RM, Bombardier C, Goldenberg DL, Tugwell P, et al: The American College of Rheumatology 1990 criteria for the classification of fibromyalgia. Report of the multicentre criteria committee. Arthritis Rheum 1990;33:160-172.

$\checkmark 9$ Cohen ML, Quintner JL: Fibromyalgia syndrome, a problem of tautology. Lancet 1993; 342:906-909.

10 Bennett RM: Current issues concerning management of the fibrositis/fibromyalgia syndrome. Am J Med 1986;81(suppl 3A):15-18.
11 Hopwood MB, Abram SE: Factors associated with failure of trigger point injections. Clin $\mathrm{J}$ Pain 1994;10:227-234.

12 Hong CZ, Hsueh TC: Difference in pain relief after trigger point injections in myofascial pain patients with and without fibromyalgia. Arch Phys Med Rehabil 1996;77:1161-1166.

13 Wolfe F, Simons DC, Fricton J, Bennett RM, Goidenberg DL, Gerwin R, Hathaway D, et al: The fibromyalgia and myofascial pain syndromes: A preliminary study of tender points and trigger points in persons with fibromyalgia, myofascial pain syndrome and no disease. $\mathbf{J}$ Rheumatol 1992;19:944-951.

14 Croft P, Schollum J, Silman A: Population study of tender point counts and pain as evidence of fibromyalgia. BMJ 1994;309:696699.

15 Durette MR, Rodriquez AA, Agre JC, Silverman JL: Needle electromyographic evaluation of patients with myofascial or fibromyalgic pain. Am J Phys Med Rehabil 1991;70:154156.

16 Mense S: Considerations concerning the neurobiological basis of muscle pain. Can J Physiol Pharmacol 1991;69:610-616.

17 Mense S: What is different about muscle pain? Schmerz 2003; 17:459-463.

18 Bennett RM: Fibromyalgia and the disability dilemma: A new era in understanding a complex, multidimensional pain syndrome. Arthritis Rheum 1996;39:1627-1630.
19 Komaroff AL, Buchwald D: Symptoms and signs of chronic fatigue syndrome. Rev Infect Dis 1991;13:S8-S11.

20 Aaron LA, Burke MM, Buchwald D: Overlapping conditions among patients with chronic fatigue syndrome, fibromyalgia, and temporomandibular disorder. Arch Intern Med 2000; 160:2398-2401.

21 Buchwald D: Fibromyalgia and chronic fatigue syndrome: Similarities and differences. Rheum Dis Clin North Am 1996;22:219-243.

22 Travell J, Rinzler SH: The myofascial genesis of pain. Postgrad Med 1952;11:425-434.

23 Simons DC, Travell JG: Myofascial pain syndromes; in Wall PD, Melzack R (eds): Textbook of Pain, ed 2. Edinburgh, Churchill Livingstone, 1989, pp 368-385.

24 Mills KR, Newham DJ, Edwards RHT: Muscle pain; in Wall PD, Melzack R (eds): Textbook of Pain, ed 2. Edinburgh, Churchill Livingstone, 1989, pp 420-432.

25 Swerdlow B, Dieter JNI: An evaluation of the sensitivity and specificity of medical thermography for the documentation of myofascial trigger points. Pain 1992;48:205-213.

26 Fricton JR: Myofascial pain syndrome: Characteristics and epidemiology; in Fricton JR, Awad E (eds): Advances in Pain Research and Therapy: Myofascial Pain and Fibromyalgia Syndrome. New York, Raven Press, 1990, vol 17, pp 107-127. 
27 Travell JG, Simons DG (eds): Myofascial Pain and Dysfunction: The Trigger Point Manual Baltimore, Williams \& Wilkins, 1983.

28 Simons DG: Review of enigmatic MTrPs as a common cause of enigmatic musculoskeletal pain and dysfunction. J Electromyogr Kinesiol 2004;14:95-107.

$29 \mathrm{http} / / /$ websites.golden-orb.com/pain-education/100103.php.

30 Lewis T: Suggestions related to the study of somatic pain. Br Med J 1938;1:321-325.

31 Kellgren JH: Observations on referred pain arising from muscle. Clin Sci 1938;3:175-190.
32 Wall PD: The mechanisms of pain associated with cervical vertebral disease; in Hirsch $\mathrm{C}$, Zotterman Y (eds): Cervical Pain. Oxford, Pergamon Press, 1971, pp 201-210.

33 Feinstein B, Langton JNK, Jameson RM, Schiller F: Experiments on pain referred from deep somatic tissues. J Bone Joint Surg 1954; 36A:981-997.

34 Hromada J: On the nerve supply of the connective tissue of some peripheral nervous components. Acta Anat 1963;55:343-351.

35 Asbury AK, Fields HL: Pain due to peripheral nerve damage: A hypothesis. Neurology (Minneap) 1984;34:1587-1590.

36 Thomas PK: Pain in peripheral neuropathy: Clinical and morphological aspects; in Culp WJ, Ochoa J (eds): Abnormal Nerves and Muscles as Impulse Generators. New York, Oxford University Press, 1982, pp 553-567.
37 Hardy TD, Wolff HO, Goodell H: Experimental evidence on the nature of secondary hyperalgesia. J Clin Invest 1950;29:115-140.

38 Xavier AY, Farrell CE, McDanal J, Kissin I: Does antidromic activation of nociceptors play a role in sciatic radicular pain? Pain 1990;40: 77-79.

39 Dubner R: Neuronal plasticity in the spinal and medullary dorsal horns: A possible role in central pain mechanisms, in Casey KL (ed): Pain and Central Nervous System Disease: The Central Pain Syndromes. New York, Raven Press, 1991, pp 143-155. 